\title{
The Impact of Aging Agricultural Labor Population on Farmland Output: From the Perspective of Farmer Preferences
}

\author{
Guancheng Guo, Qiyu Wen, and Jingjuan Zhu \\ College of Public Administration, Nanjing Agricultural University, Nanjing 210095, China \\ Correspondence should be addressed to Jingjuan Zhu; zhujingjuan@njau.edu.cn
}

Received 9 April 2015; Accepted 30 May 2015

Academic Editor: Ruihua Liu

Copyright (c) 2015 Guancheng Guo et al. This is an open access article distributed under the Creative Commons Attribution License, which permits unrestricted use, distribution, and reproduction in any medium, provided the original work is properly cited.

\begin{abstract}
Chinese agriculture is facing an aging workforce which could negatively impact the industry. In this context, research is needed on how work preferences and age of farmers affect agricultural output. This paper attempts to investigate these factors to more fully understand the impact of an aging agricultural labor population on agricultural production. The results show that, in this context of aging, changes in the working-age households have a significant impact on agricultural output. Despite the fact that the impacts of intention to abandon land management were not significant, we can ignore this preference in the workforce. The combination of changes in the composition of the working-age households indicates that 58.53 percent of the agricultural producers will likely quit. This is a potential threat for the future of agricultural development. We also found that elderly farmers who do not intend to abandon farming had higher agricultural output compared to other farmers. This indicates that the adverse effects of changes in the agricultural population age result more from the agricultural output of older farmers who intend to give up farming. This intention adversely affected other elements and reduced investment. Therefore, various forms of training should increase efforts to cultivate modern professional farmers and policies should be simultaneously developed to increase agricultural production levels.
\end{abstract}

\section{Introduction}

Aging agricultural labor forces are the trend in many parts of the world including China. Both the second national agricultural census and preliminary research have shown that Chinese agriculture is facing an aging workforce; the share of older population in the total labour force reaches $32.5 \%$. In this context, people are increasingly worried about how the aging of the agricultural labor force will affect the output of agricultural land and whether aging agricultural producers will continue to engage in agricultural production [1]. There is a substantial body of scholarly literature on aging agricultural labor forces. Tang and MacLeod suggested that older workers are, on average, less productive than younger workers and that labor force aging has a modest negative direct impact on productivity growth in Canada [2]. The research of $\mathrm{Li}$ and Zhao showed that the agricultural labor force in Liaoning Province of China exhibited an "aging" phenomenon and that agricultural labor "aging" is not conducive to the overall development of agricultural production [3]. In particular, Siliverstovs et al. found that an increase in aging exerts a statistically significant adverse effect on the employment shares in agriculture, manufacturing, construction, and mining and quarrying industries [4]. Yang et al. have studied the impact of agricultural labor force age on agricultural land use efficiency in regions with different levels of economic development, and their conclusion was that the households with primarily young labors have lower land use efficiency than the households where the labor is mainly done by older individuals [5]. Woodsong found that in Jamaica, where agriculture occupies an important place in the life course of many elders, the rural concentration of elders may have negative consequences for agricultural production [6]. Zhang et al. found, surprisingly, that the household proportion of males among agricultural laborers did not significantly influence the occurrence of land abandonment at the parcel level, probably due to the male agricultural laborers being overwhelmingly old (average age greater than 56 years) [7]. These scholars believe that the aging of the existing agricultural labor force has an impact on agricultural production. However, a study by $\mathrm{Hu}$ and Zhong using rural fixed observation point data to quantify the planting 
decisions and investment levels of elderly farmers and young farmers concluded that rural aging at this stage does not have a negative impact on China's grain production [8]. Another study by these two authors concluded that crops with less collective decision making and a lower degree of mechanization experience a greater impact from aging [9]. In previous studies, the potential spatial spillover effect of transportation infrastructure on economic output in the US agricultural sector has not been properly taken into account given the sector's importance in the economy and dependence on transportation. The results of Tong and other researchers suggest that road disbursement in a given state has positive direct effects on its agricultural output [10]. Based upon the China Health and Nutrition Survey, a multivariate analysis demonstrated that the migration of household members increased the time spent on farm work and domestic work by the remaining elderly and children [11]. Chen et al. showed that the combined effect of rural household population aging and the transfer of rural labor force is a premature aging of the rural population and excessive reduction in the primary sector employees which will affect industry growth [12]. He hypothesizes that the aging agricultural labor force has a negative impact on effective use of land resources, food security agricultural modernization, the reproduction of agricultural emotions, and the rural grass-roots support system [13]. The research of L. Li and Y. Li reached a similar conclusion [14]. Today, the European Union is consequently faced with a dual problem: the scarcity of new and young farmers and the rapid aging of the farmer population. Given the context of an aging agricultural labor force, the future of the farmers' profession must be ensured. Manton examined sociodemographic and health conditions in Brazil, Russia, India, and China and the potential effects of population and labor force aging on economic growth [15].

Few studies explicitly look at how farmer preferences (give up farmland or not) affect agricultural output. Research in this area has mainly focused on macroscopic factors, including agricultural subsidies, agricultural production prices, food prices, and industrial management [16-18]. Clark et al. hypothesize that industrial changes such as a decline in the proportion of the labor force employed in agriculture will lower the proportion of older persons in the labor force [19]. Given the background of aging labor forces, it is necessary to conduct research on the impact of an aging agricultural labor population on farmland output as this is related to the sustainable development of agriculture and food security issues in China. Roberts conjectured that village-based networks are important in channeling migrants into particular occupations and destinations, undermining the notion of a "blind" migration from rural areas to coastal cities during China's rapid economic transition [20]. D'Antoni et al. found that, from 1939 to 2007, increased direct government payments resulted in greater migration of labor from agriculture [21]. As Goletti and Chabot report, more research is called for on input and output market efficiency, private sector development, the effects of reform on farmers, sequencing issues, comparative advantage, water management, land tenure, and farm size [22]. From 1939 to 2007 , increased direct government payments resulted in greater migration of labor from agriculture [23]. Government policy appears to have had limited success at sustaining the agricultural labor force.

In summary, the effect of agricultural labor force aging on agricultural production, as well as the influence of farmer preferences on agricultural production, has been rarely considered. This paper attempts to develop an analytical framework to more comprehensively study the agricultural labor force in the context of aging farmers and the impact of farmer preferences. The rest of the paper is organized as follows. In Section 2, this paper attempts to give an theoretical analysis, and Section 3 introduces data and does some analysis, and finally conclusions and discussion are done in Section 4.

\section{Theoretical Analysis}

Agricultural production depends on natural conditions, factor input, and the prevailing level of technology. Natural conditions for agricultural production are not controllable, so the analysis of influencing factors of agricultural real estate is concentrated mainly on factor input, technical level, and other indirect factors. The agricultural population aging concerns in this paper are among the indirect factors.

Furthermore, agricultural production requires the joint participation of labor, machinery, fertilizers, pesticides, and land and among elements. Agricultural producers will adjust these elements depending on the conditions of rational expectations and judgment experience. In theory, farmers that expect to continue production in the future will have significantly different factor input compared to farmers who do not intend to continue to engage in agricultural production. Furthermore, agricultural producers of different ages make different choices regarding input elements.

Physical strength is required during the process of agricultural production. For adult producers, there is first an increase in physical strength that culminates in middle age. The decline in physical strength after middle age necessitates a greater investment of labor for the same production activities. However, the experience of older farmers leads to more efficient combinations of input, which makes a unit of labor more effective.

Agricultural production requires not only labor input, but also technological development. On the one hand an aging agricultural production needs technology to compensate for physical deficiency. On the other hand, nonfarm payrolls make the opportunity cost of agricultural labor input large. This may incline them to invest in the use of machinery instead of labor input.

Agricultural knowledge and skills in agriculture, such as production, operation, and management, increase with age. The accumulated knowledge and skills help farmers maximize the efficient use of agricultural input, such as pesticides and fertilizers, as well as labor input.

Land is the basis for agricultural production. Currently, rural land is implemented under the Household Contract Responsibility System, which is a basic land institution in rural China. From the farmers' perspective, a different family will manage different agricultural land area caused by its population. Although many Chinese rural villages stopped 
TABLE 1: Study region.

\begin{tabular}{lcccc}
\hline Region & Municipal city & County & Number of samples & Effective sample size \\
\hline \multirow{3}{*}{ Northern Jiangsu } & Yancheng & Yandu, Dongtai, Sheyang & 261 & 211 \\
& Suqian & Suyu, Siyang, Sihong & 261 & 183 \\
& Xuzhou & Tongshan, Xinyi, Fengxian & 261 & 191 \\
\hline \multirow{2}{*}{ Central Jiangsu } & Nantong & Gangzha, Haimen, Rugao & 261 & 140 \\
& Yangzhou & Jiangdu, Yizheng, Baoying & 261 & 159 \\
\hline \multirow{2}{*}{ Southern Jiangsu } & Suzhou & Wuzhong, Changshu, Kunshan & 261 & 25 \\
& Zhenjiang & Zhenjiang New Area, Dantu, Danyang & 70 \\
\hline
\end{tabular}

farmland adjustments, the agricultural producers can still select planting acreage, and the agricultural producers of different age groups will select modest acreage according to their own conditions.

Individual preferences and the overall labor force are employed to analyze the effect of age, but combining the two to analyze the situation of agricultural real estate will yield new insights. We separated the farmers into four categories: old farmers who do not intend to abandon farming (ONA), old farmers who intend to abandon farming $(\mathrm{OA})$, young farmers who intend to give up farming (YA), and young farmers who do not intend to give up farming (YNA). For YA farmers, interest in the agricultural production is not high and incentives to increase output from the agricultural land are not high; plus they lack experience in agricultural production. Thus, YA farmers would be less concerned about agricultural land, and input will be insufficient. For ONA farmers, they lack physical strength, but they are still reluctant to give up agricultural production. Thus, they will try to compensate for their lack of physical strength through additional supplies, and so forth. Thus, ONA farmers desire production input more than other groups and they possess long-term production experience. These factors should lead to higher levels of input and outputs compared to other groups. For YNA, they are willing to engage in agricultural production and usually benefit from family experience as most agriculture is the same as that done traditionally. So they will not reduce the input, and their output can be higher than YA. For OA farmers, their interest to continue in agricultural production is not high, so they do not focus on improving the agricultural land and pursue more short-term benefits. Their advantage lies in the long-term accumulation of experience in agricultural production, input configuration is relatively reasonable, and the output of agricultural land will be relatively moderate.

In addition, based on previous studies, there are also many other factors which can affect farmer input and agricultural output. Farmer's cultural level and skills [24], the degree of farmland fragmentation $[25,26]$, and farmland transfer cases [26] also affect the situation of farmers. In China, farmland transfer usually means that farmland moves from one farmer to another farmer which increases the total farmland of the latter. Therefore, a study from the perspective of farmer preferences needs to examine the impact of the cultural level of farmers and the degree of land fragmentation on agricultural output.
Based on the above analysis, this study uses econometric models to analyze the impact of farmer preferences on agricultural output.

\section{Data and Analysis}

3.1. Study Area. This study uses the data from the Jiangsu Provincial Department and was conducted in cooperation with Nanjing Agricultural University, Jiangsu province, rural land issues hundred villages research. The survey involved a total of seven municipal cities in Jiangsu; a total of 1827 questionnaires were collected by a random sampling. And 3 counties are selected in every municipal city which represent various economic development level. We excluded questionnaires that were invalid for purposes of this study. This left 979 household level questionnaires which were used to meet the research needs of this paper (Table 1).

Jiangsu province is located on the eastern coast of China. It spans $116^{\circ} 18^{\prime}-121^{\circ} 57^{\prime}$ longitude and $30^{\circ} 45^{\prime}-35^{\circ} 20^{\prime}$ latitude with an area of $102,600 \mathrm{~km}^{2}$. It accounts for at least 1.06 percent of China's per capita land area in Chinese provinces and autonomous regions. Jiangsu has become the province with the highest level of development as China has entered the "upper-middle" level of developed countries. Different cities in Jiangsu differ in economic development. Generally, the economic development is best in the southern cities, including Nanjing, Zhenjiang, Changzhou, Wuxi, and Suzhou; moderate in the central cities, including Yangzhou, Nantong, and Taizhou; and lowest in northern cities, including Xuzhou, Lianyungang, Suqian, Huai'an, and Yancheng.

\subsection{Descriptive Analysis}

3.2.1. The Basic Characteristics of Household Age. The age of farmers used herein refers to the average age of the main labor force engaged in agricultural production. A study by Burton supports the reasonableness of this treatment method [27]. Figure 1 shows the age distribution of the main labor force in agricultural production in the northern part of Jiangsu, central Jiangsu, and southern Jiangsu classification.

The total average age was 56.6 years. The average in the area with the highest degree of economic development in the southern region was 54.8 years old, the average in the least developed economies in the north was 55.8 years old, and the average in the central region was 58.6 years old. We conjecture that the economically developed southern portion 
TABLE 2: Agricultural factor input of different types of farmers.

\begin{tabular}{lccccccccc}
\hline & API (RMB/mu) & AA (years) & EL & LI (person) & AOA (mu) & OFB (blocks) & SI (RMB/mu) & PI (RMB/mu) & FI (RMB/mu) \\
\hline OA & 1924.31 & 66.69 & 2.29 & 1.54 & 4.79 & 3.62 & 122.97 & 131.26 & 262.35 \\
ONA & 2215.90 & 66.14 & 2.38 & 1.57 & 6.53 & 3.89 & 149.64 & 156.29 & 310.58 \\
YA & 1631.56 & 49.33 & 3.19 & 1.27 & 7.94 & 3.76 & 133.64 & 97.52 & 243.26 \\
YNA & 1883.34 & 49.19 & 3.24 & 1.40 & 13.14 & 5.28 & 137.84 & 125.79 & 261.62 \\
\hline GF & 1776.91 & 58.01 & 2.74 & 1.40 & 6.37 & 3.69 & 128.30 & 114.39 & 252.80 \\
NGF & 2048.61 & 57.67 & 2.81 & 1.48 & 9.84 & 4.59 & 143.74 & 141.04 & 286.10 \\
OF & 2068.78 & 66.41 & 2.34 & 1.55 & 5.66 & 3.76 & 136.30 & 143.77 & 286.46 \\
YF & 1756.74 & 49.26 & 3.22 & 1.33 & 10.54 & 4.52 & 135.74 & 111.66 & 252.44 \\
\hline
\end{tabular}

Note: GF refers to the farmers who want to give up farmland and NGF refers to the farmers who do not want to give up farmland. OF signifies old farmers and YF signifies young farmers. API refers to agriculture operating income in 2012. AA refers to average age. EL refers to education level. LI refers to labor input. AOA refers to actual operating area. OFB refers to operating farmland blocks. SI refers to seed input. PI refers to pesticide input. FI refers to fertilizer input. $\mathrm{mu}$ is a popular area unit in China which equals $0.067 \mathrm{ha}$. The age and education level are the averages of the major agricultural labor households. Less than 30 years old is considered young in this research, and the age more than 60 is considered old.

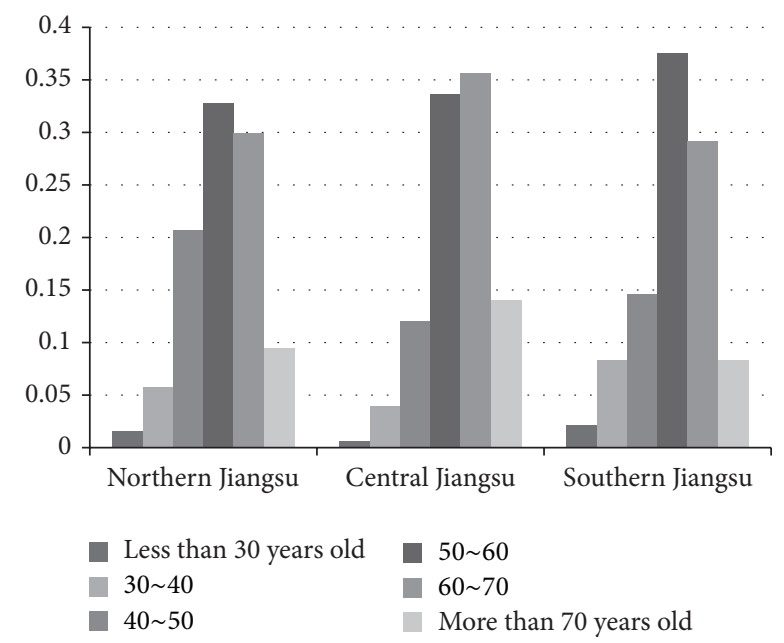

FIGURE 1: The age proportion distribution in different regions of Jiangsu province.

of Jiangsu attracted workers away from the central region, thereby exacerbating the aging of the rural workforce in the central region. This may help explain why the central region has a higher average farmer age compared to the less economically developed northern region.

We can see from Figure 1 that the phenomenon of an aging agricultural labor force is an objective reality. The peaks were mainly in the 50 to 60 and the 60 to 70 age categories. The agricultural producers in northern and southern Jiangsu have age distribution peaks between 50 and 60 years, but the central region has its peak in the 60 to 70 age category. This also confirms that the agricultural labor force aging in the Jiangsu central region is more serious than the other regions.

\subsubsection{Different Types of Farmers in Agricultural Production} Factor Input Feature. To further examine the impact of age on agricultural production, we investigated old farmers who do not intend to abandon farming (ONA), old farmers who intend to abandon farming (OA), young farmers who intend to give up farming (YA), and young farmers who do not intend to give up farming (YNA) to discover potential differences in input and output.

After comparing the different types of farmers in terms of agricultural production and input-output (see Table 2), we found that the differences were not great. ONA farmers had the highest operating income in agriculture, in terms of average per mu of view. This may partly reflect greater experience in production but also may indicate additional investment. YA farmers had the lowest operating income; it may be that YA farmers are more inclined to engage in nonagricultural industries and pursuit income from nonagricultural sectors. However, YNA have a much higher total agricultural operating income compared to the other three groups. This is mainly because they have expanded their producing land area, and the proportion of the YNA group reached $41.47 \%$ in the whole sample.

From the investment point of view, most of the operating area is attributable to YNA farmers, followed by YA, and relatively little attributable to elderly farmers. This may be due to a physical decline in elderly farmers. ONA farmers had the greatest investment in seeds, fertilizers, and pesticides. This might be to compensate for a decrease in labor input. OA and YNA farmers had comparable values for seed, fertilizer, and pesticide input. However, the total values for OA farmers were far below other groups. YA farmers invested the least amount of labor.

Input and outputs were lower for those intending to abandon farming regardless of age, indicating that this intention is not conducive to improving agricultural production. However, the influence of this negative effect requires further analysis. Although older farmers have higher input than the young farmers do, they also have higher output than young farmers. Thus, we cannot conclude from this statistical data how the aging agricultural population will affect the use of agricultural land.

Simply examining the descriptive statistics is not sufficiently comprehensive. However, the descriptive statistics appear to support our analytical framework. 
From the general description of the above simple analysis, we cannot accurately separate the impacts of farmer preferences. Therefore, we used an econometric model to analyze the above conclusions more fully.

\subsection{Econometric Analysis}

3.3.1. Model Selection. In this paper, an extended production function is used to study the problems associated with the aging of the agriculture labor force. The model is built on the C-D production function, but its form is altered for more flexibility. The basic form of the model is as follows:

$$
\ln Y_{i}=\beta_{0}+\sum_{j} \beta_{j} \ln x_{i j}+\frac{1}{2} \sum_{j} \sum_{m} \beta_{j m} \ln x_{i j} \ln x_{i m}+\delta,
$$

where $Y$ represents the operating income of farmers, $x$ represents farmers' factor input, and $i$ indicates individual farmers. $j$ and $m$ represent input element number. We modified the basic equation (1) with the introduction of relevant variables. In this way, we obtained the model shown in

$$
\begin{aligned}
\ln Y_{i}= & c+\beta_{1} \ln x_{i t}+\beta_{2} \ln x_{i l}+\beta_{3} \ln x_{i z}+\beta_{4} \ln x_{i f} \\
& +\beta_{5} \ln x_{i n}+\frac{1}{2} \beta_{11}\left(\ln x_{i t}\right)^{2}+\frac{1}{2} \beta_{22}\left(\ln x_{i l}\right)^{2} \\
& +\frac{1}{2} \beta_{33}\left(\ln x_{i z}\right)^{2}+\frac{1}{2} \beta_{44}\left(\ln x_{i f}\right)^{2} \\
& +\frac{1}{2} \beta_{55}\left(\ln x_{i n}\right)^{2}+\beta_{12} \ln x_{i t} \ln x_{i l} \\
& +\beta_{13} \ln x_{i t} \ln x_{i z}+\beta_{14} \ln x_{i t} \ln x_{i f} \\
& +\beta_{15} \ln x_{i t} \ln x_{i n}+\beta_{23} \ln x_{i l} \ln x_{i z} \\
& +\beta_{24} \ln x_{i l} \ln x_{i f}+\beta_{25} \ln x_{i l} \ln x_{i n} \\
& +\beta_{34} \ln x_{i z} \ln x_{i f}+\beta_{35} \ln x_{i z} \ln x_{i n} \\
& +\beta_{45} \ln x_{i f} \ln x_{i n}+\beta_{6} d_{i a}+\beta_{7} d_{i b}+\beta_{8} o_{i} \\
& +\beta_{9} w_{i}+\beta_{10} s_{i}+\beta_{16} l z_{i}+\beta_{17} d s_{i}+\delta,
\end{aligned}
$$

where $c$ represents the constant term, $t$ indicates land investment, $l$ represents labor input, $z$ represents the seed investment, $f$ represents fertilizer input, $n$ represents pesticide input, $d$ represents the type of farmers ( $a$ refers to ONA farmers and $b$ refers to YA farmers), $o$ represents age, $w$ represents education level, $s$ indicates the degree of land fragmentation represented by the number of blocks, $l z$ indicates whether the land is transferred (1 indicates transfer and 0 indicates no transfer), $d s$ indicates whether they intend to give up land management ( 1 signifies yes and 0 signifies no), and the other symbols are the same as above.

3.3.2. Model Estimation Results. The investigation was related to farmers in agricultural production data into (2); derived model estimation results are shown in Table 3.

The $R$-squared of the model was 0.634456 . The ONA farmers, labor input, seed investment, land investment, farmers age, education level of farmers, land fragmentation degree,
TABLE 3: Extended production function parameter estimates.

\begin{tabular}{lcc}
\hline The independent & Parameters & $t$ value \\
variables & -0.090977 & -1.043367 \\
\hline$d s$ & -0.253916 & -0.793467 \\
$\ln (f)$ & $0.145951^{* *}$ & 2.020194 \\
$\ln (f) \times \ln (f)$ & $0.967351^{*}$ & 1.872886 \\
$\ln (l)$ & -0.063184 & -0.557116 \\
$\ln (l) \times \ln (f)$ & -0.143250 & -0.402932 \\
$\ln (l) \times \ln (l)$ & 0.042504 & 0.418499 \\
$\ln (l) \times \ln (n)$ & 0.052057 & 0.527355 \\
$\ln (l) \times \ln (t)$ & -0.106429 & -1.110889 \\
$\ln (l) \times \ln (z)$ & -0.163946 & -0.576910 \\
$\ln (n)$ & -0.032321 & -0.562985 \\
$\ln (f) \times \ln (n)$ & 0.073402 & 1.271503 \\
$\ln (n) \times \ln (n)$ & $-0.007494^{*}$ & -1.665416 \\
$s$ & -0.120524 & -1.256796 \\
$d b$ & $1.691591^{* * *}$ & 7.545998 \\
$\ln (t)$ & $-0.183415^{* * *}$ & -2.955062 \\
$\ln (t) \times \ln (f)$ & 0.076468 & 1.263808 \\
$\ln (t) \times \ln (n)$ & $0.170023^{* * *}$ & 3.318696 \\
$\ln (t) \times \ln (t)$ & $-0.111609^{* *}$ & -2.257393 \\
$\ln (t) \times \ln (z)$ & $0.048475^{*}$ & 1.695400 \\
$w$ & $-0.374512^{*}$ & -1.716832 \\
$\ln (z)$ & 0.002678 & 0.057721 \\
$\ln (z) \times \ln (f)$ & -0.016682 & -0.383357 \\
$\ln (z) \times \ln (n)$ & $0.122659^{* * *}$ & 2.919681 \\
$\ln (z) \times \ln (z)$ & $0.138489^{*}$ & 1.840943 \\
$d a$ & $-0.288300^{*}$ & -1.794592 \\
$o$ & -0.106429 & -1.110889 \\
$l z$ & $1.04 E-10$ & $4.60 E-09$ \\
\hline & -10 & $5 \%$ \\
\hline & & \\
& &
\end{tabular}

Note: the symbols $* * *$, **, and $*$, respectively, indicate $1 \%, 5 \%$, and $10 \%$ confidence levels via significant testing, Log-likelihood $=-1031.225$.

fertilizer input secondary effect, secondary effects of land investment, secondary effects of seed investment, and land and fertilizer interaction, as well as interaction of land and seeds show a significant impact on agricultural production. The impacts of other factors on agricultural output were not significant.

The regression coefficient for the age of individual farmers is -0.288300 and is significant at the $10 \%$ confidence level. This indicates that older farmers negatively affected agricultural. Increased age is not conducive to improving agricultural output. The additional input and experience of the older farmers are not enough to compensate for the adverse effect of their age. In addition, elderly farmers appear to resist new technologies in agricultural production. When asked whether they make use of machinery, young farmers $(84.331 \%)$ answered that they mainly used machinery at a higher rate than older farmers (77.566\%). The regression coefficient of "intention to abandon land management" variable was -0.090977 , indicating that this intention has 
a negative effect on agricultural output. We can imagine that, sometime in the future, those who intend to give up farming will reduce spending on agriculture. The data in Table 2 also show that farmers who intended to abandon the profession had lower investment in seed, fertilizer, and pesticides input. Objectively speaking, we can presume that both those who intend to abandon farming and older farmers who do not intend to abandon farming will gradually withdraw from active or passive agricultural production. Although YNA farmers make up $41.47 \%$ of the total, nearly $58.53 \%$ of the agricultural producers will likely exit agricultural production in the near future. On the one hand, YNA farmers may take the initiative to seek another income. On the other hand, older farmers are faced with the situation of retirement regardless of intentions. Thus, although our analysis indicates that this effect is not significant at present, the problem of agricultural production successors still requires attention. However, older farmers who do not intend to abandon the profession significantly improve agricultural output at the $10 \%$ level. We conjecture that this is because of their greater experience and higher levels of investment in factor input. Young people who intend to abandon farming do not help improve agricultural output, but this effect is not significant.

We also found that labor, seed, and land investment have a significant impact on agricultural output. In addition, a higher educational level and reducing the degree of fragmentation of land are conducive to improving agricultural productivity. The secondary effects of fertilizer input, the secondary effects of land investment, and the secondary effects of seed investment, land, and fertilizer interaction, as well as the interaction of land and seeds also show a significant impact on agricultural output, which indicates that a reasonable mix of factor input can increase agricultural output.

\section{Conclusions and Discussion}

These results show that in the context of an aging agricultural labor force, changes in the working-age households have a significant impact on agricultural output. Concern is needed for such adverse effects. Although the influence of intention to abandon land management was not significant, we cannot ignore this effect because changes in the composition of the working-age households suggest that 58.53 percent of the agricultural producers will likely exit agricultural production. This represents a potential threat to the future development of agriculture. We also found that the elderly who do not intend to abandon the farmers compared to other farmers more conducive to agricultural output, indicating that the adverse effects of changes in the agricultural population age more agricultural output from older farmers intend to give up, and this negative impact can be reduced by an additional investment in other elements.

The aging agricultural labor force trend has become widely accepted. To reduce the adverse impact on agricultural output caused by aging in the context of food security is the current problem we are facing. We believe policy proposal should start with the following considerations.
First, increase the intensity of various forms of training to nurture professional farmers. In the next few years, the trend of urbanization will transfer more young people from rural areas and exacerbate the aging problem. Various training should be conducted to improve scientific and technological level as well as cultural attitudes. This training should equip them with more modern agricultural production skills to make up for the problems caused by aging.

Secondly, develop different policies to increase agricultural production levels for different types of farmers. For example, farmers intending to abandon the profession should be encouraged to carry out the land transfer and split the land contract and management rights, thus promoting largescale production agriculture. We should help young people who do not intend to abandon the farming to improve their skills, increase financial support, expand operation scale, and ultimately modernize and industrialize agricultural production.

\section{Conflict of Interests}

The authors declare that there is no conflict of interests regarding the publication of this paper.

\section{Acknowledgments}

This work was supported in part by the National Natural Science Foundation of China (Grant nos. 71233004 and 71003052), the Project Guide Research Fund of Philosophy and Social Science in Colleges and Universities in Jiangsu (Grant no. 2014SJD076), and the Fundamental Research Funds for the Central Universities of Nanjing Agricultural University (Grant nos. SK2013005 and SKPT2014046).

\section{References}

[1] B. Lin and H. Deng, "An empirical analysis of the agricultural labor force aging on the impact of land use efficiency-based in Zhejiang Province rural fixed observation point data," Chinese Rural Economy, no. 4, pp. 15-25, 2012.

[2] J. Tang and C. MacLeod, "Labour force ageing and productivity performance in Canada," Canadian Journal of Economics, vol. 39, no. 2, pp. 582-603, 2006.

[3] M. Li and L. Zhao, “Agricultural labor 'aging' phenomenon and its impact on agricultural production-based on empirical analysis of Liaoning Province," Issues in Agricultural Economy, no. 10, pp. 12-18, 2009.

[4] B. Siliverstovs, K. A. Kholodilin, and U. Thiessen, "Does aging influence structural change? Evidence from panel data," Economic Systems, vol. 35, no. 2, pp. 244-260, 2011.

[5] J. Yang, G. Yang, and X. Hu, "Age effects on the agricultural labor force farmers cultivated land use efficiency-evidence from different levels of economic development in the region," Resources Science, no. 9, pp. 1691-1698, 2011.

[6] C. Woodsong, "Old farmers, invisible farmers: age and agriculture in Jamaica," Journal of Cross-Cultural Gerontology, vol. 9, no. 3, pp. 277-299, 1994.

[7] Y. Zhang, X. Li, and W. Song, "Determinants of cropland abandonment at the parcel, household and village levels in 
mountain areas of China: a multi-level analysis," Land Use Policy, vol. 41, pp. 186-192, 2014.

[8] X. Hu and F. Zhong, "The impact of population aging on crop production-analysis," Agricultural Economy Based on Wheat and Cotton Crops Issue, no. 2, pp. 36-43, 2013.

[9] X. Hu and F. Zhong, "Rural population aging impact on food production-analysis of rural fixed observation point data," Chinese Rural Economy, no. 7, pp. 29-39, 2012.

[10] T. Tong, T.-H. E. Yu, S.-H. Cho, K. Jensen, and D. de La Torre Ugarte, "Evaluating the spatial spillover effects of transportation infrastructure on agricultural output across the United States," Journal of Transport Geography, vol. 30, pp. 47-55, 2013.

[11] H. Chang, X.-Y. Dong, and F. MacPhail, "Labor migration and time use patterns of the left-behind children and elderly in rural China," World Development, vol. 39, no. 12, pp. 2199-2210, 2011.

[12] X. Chen, Y. Chen, and J. Zhang, "Quantitative study of Chinese rural population aging affect agricultural output pairs," Chinese Population Science, no. 2, pp. 39-46, 2011.

[13] X. He, "Agricultural labor force aging research-based on surveys in rural Zhejiang Province," Population and Economy, no. 2, pp. 69-78, 2013.

[14] L. Li and Y. Li, "Research on aging agricultural labor forcebased on the second national agricultural census data analysis," Agricultural Economy, no. 6, pp. 61-66, 2009.

[15] K. G. Manton, "Population and labor force aging, effect on socio-economic development in brazil, russia, india and china," International Encyclopedia of Public Health, pp. 170-181, 2008.

[16] Q. Zhou, "Factors willingness of farmers to grow grain analysis," Agricultural Technology Economic, no. 5, pp. 25-30, 2009.

[17] X. Liu, Z. Weng, and H. Zhu, "Research Jiangxi grain farmer food subsidy policy cognitive behavioral characteristics and production operations analysis," Business Research, no. 11, pp. 13-16, 2008.

[18] Y. Ma and Y. Yang, "Impact of policies on food subsidies to grain farmers will, farmers' income and production inputsan empirical case study of Hebei," Agricultural Technology Economy, no. 2, pp. 7-13, 2005.

[19] R. L. Clark, E. A. York, and R. Anker, "Economic development and labor force participation of older persons," Population Research and Policy Review, vol. 18, no. 5, pp. 411-432, 1999.

[20] K. D. Roberts, "The determinants of job choice by rural labor migrants in Shanghai," China Economic Review, vol. 12, no. 1, pp. 15-39, 2001.

[21] J. M. D’Antoni, A. K. Mishra, and A. P. Barkley, "Feast or flee: government payments and labor migration from U.S. agriculture," Journal of Policy Modeling, vol. 34, no. 2, pp. 181$192,2012$.

[22] F. Goletti and P. Chabot, "Food policy research for improving the reform of agricultural input and output markets in Central Asia," Food Policy, vol. 25, no. 6, pp. 661-679, 2000.

[23] A. Kontogeorgos, A. Michailidis, F. Chatzitheodoridis, and E. Loizou, "New Farmers' a crucial parameter for the Greek primary sector: assessments and perceptions," Procedia Economics and Finance, vol. 14, pp. 333-341, 2014.

[24] T. Schultz, Transformation of Traditional Agriculture, Commercial Press, 1987.

[25] H. Zhang and G. Yang, "Arable land fragmentation and its impact on technical efficiency of food production-beyond the micro data based on stochastic frontier production function and the number of farmers," Resources Science, no. 5, pp. 903910, 2012.
[26] T. Liu, F. Qu, J. Jin, and X. Shi, "Land fragmentation, the impact on farmers land transfer land use efficiency," Resources Science, no. 10, pp. 1511-1517, 2008.

[27] R. J. F. Burton, "An alternative to farmer age as an indicator of life-cycle stage: the case for a farm family age index," Journal of Rural Studies, vol. 22, no. 4, pp. 485-492, 2006. 


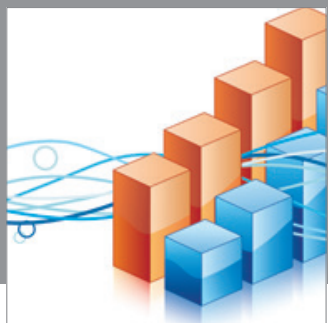

Advances in

Operations Research

mansans

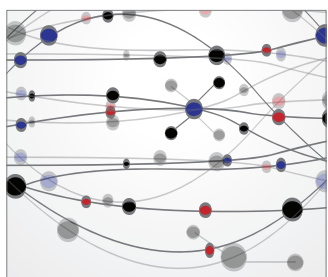

The Scientific World Journal
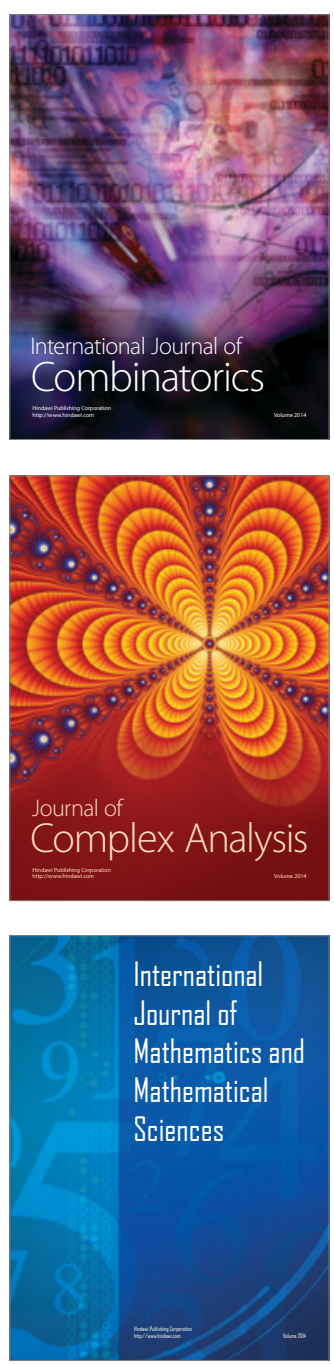
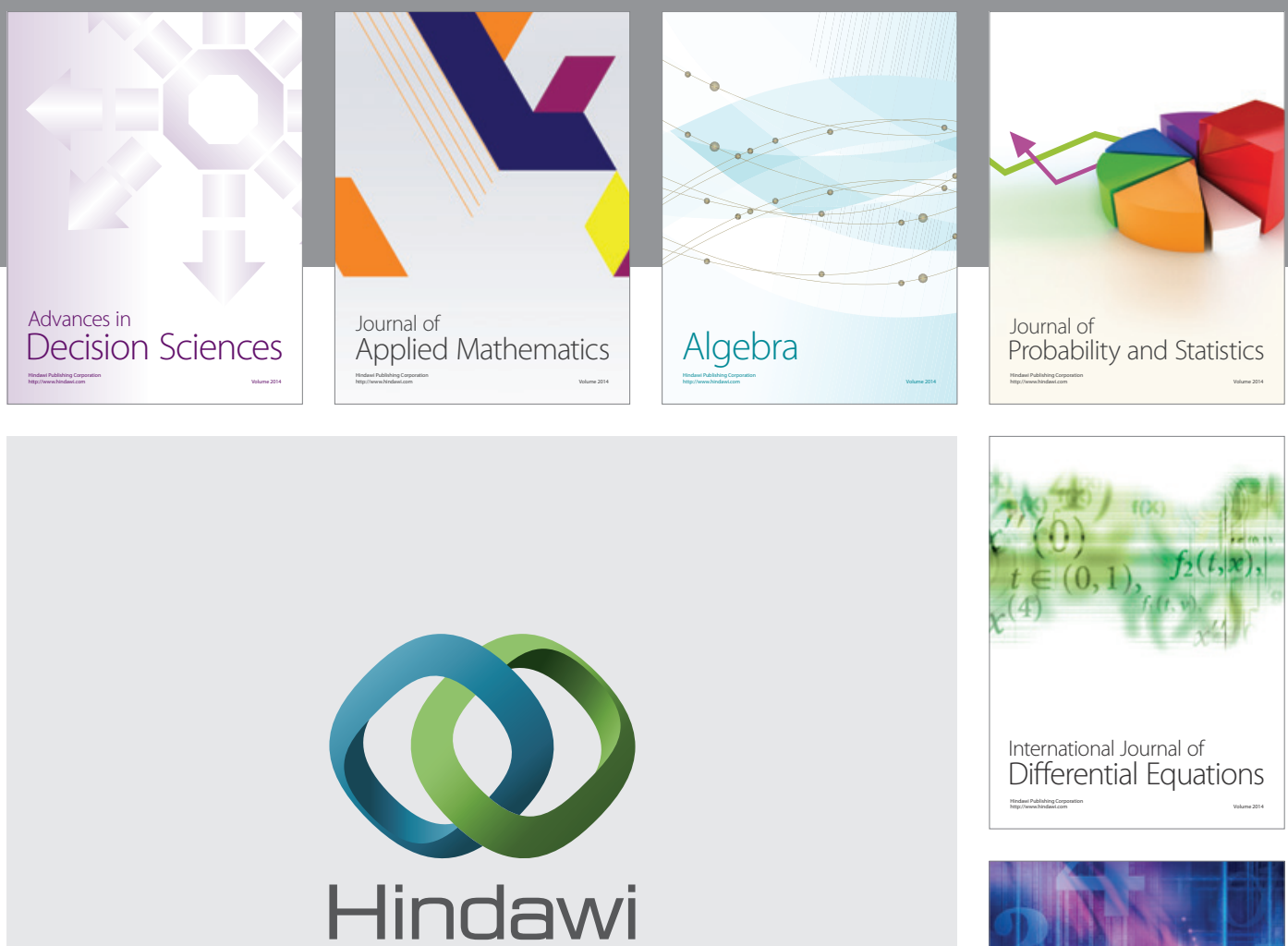

Submit your manuscripts at http://www.hindawi.com
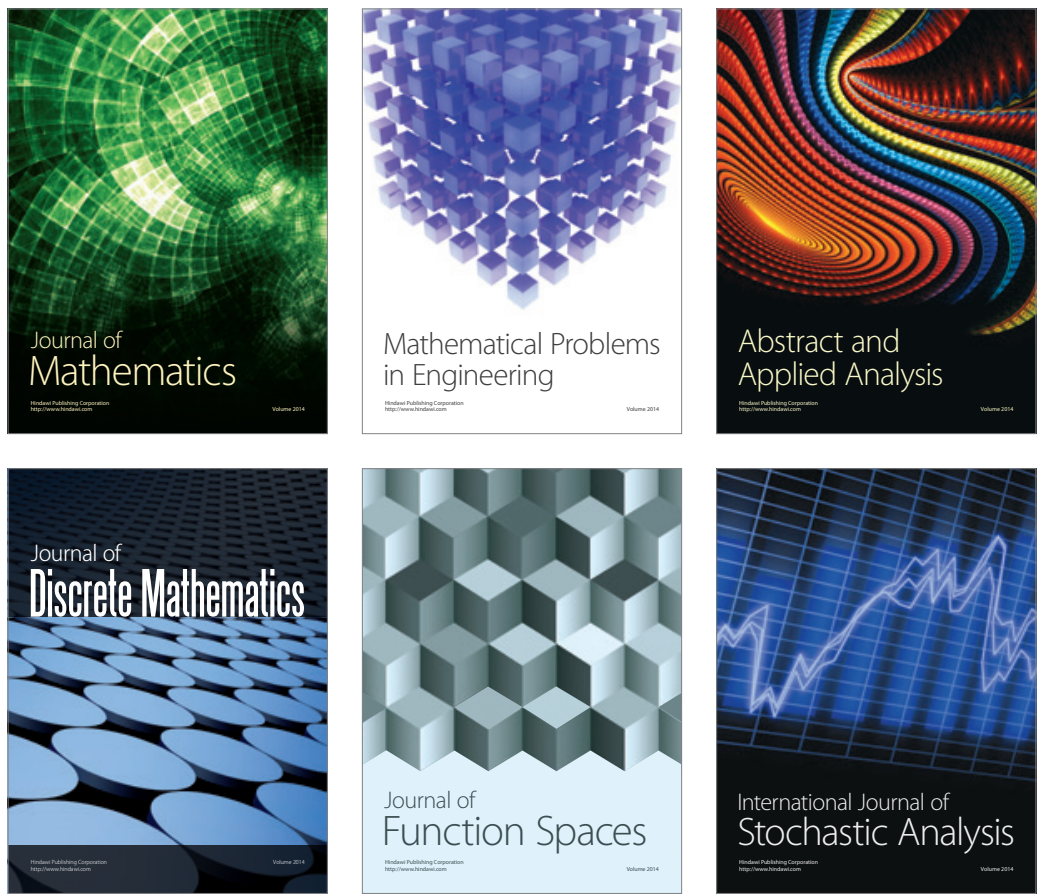

Journal of

Function Spaces

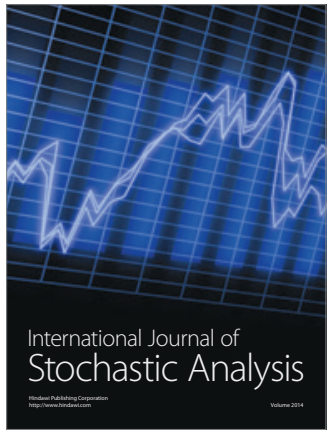

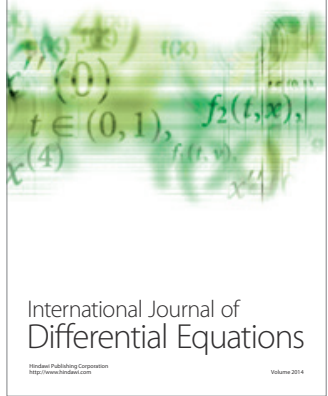
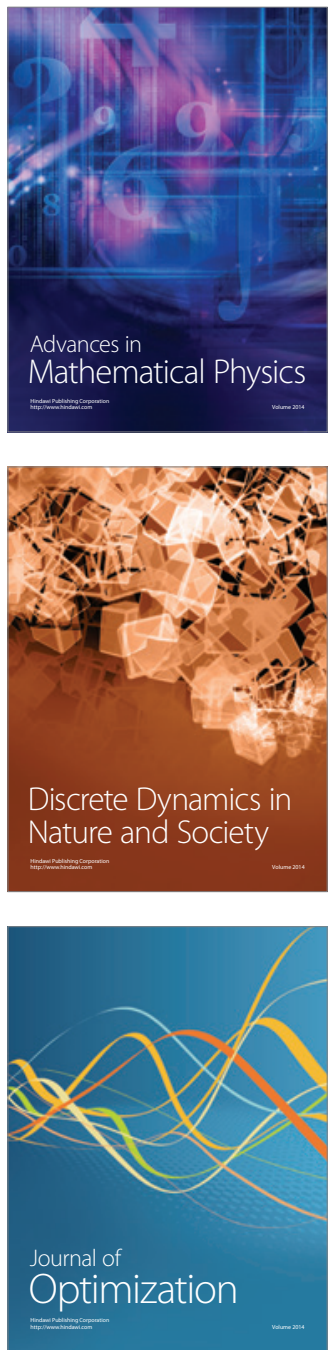